\title{
Sistemas de crédito cooperativo: defensa del modelo
}

(Cooperative credit systems: defence of the model)

\author{
Roxana Sánchez Boza ${ }^{1}$ \\ Universidad de Costa Rica
}

Recibido: 31.05.2015

Aceptado: 17.07.2015

Sumario: I. Introducción. II. Banca cooperativa. III. Crecimiento y/o fortalecimiento de las CAC-S en Centroamérica: acceso al crédito. IV. Incentivos a cooperativas y supervisión. V. Conclusiones. VI. Bibliografía.

Resumen: En el presente trabajo se analiza el papel que desarrollan las cooperativas de ahorro y crédito, en Centroamérica donde han obtenido gran impulso, especialmente en los últimos diez años. Las cooperativas de ese tipo, denominadas como entidades cooperativas de intermediación financiera por influencia de las diferentes normas legislativas que las ha introducido dentro de las reglas de control internacional por el tipo de actividad económica que realizan y obtienen beneficios de entes estatales y privados internacionales que les permite crecer.

Situación que no quita el mérito de muchas de estas organizaciones en cuanto a su competitividad en el mercado financiero y su afán por extender sus beneficios a más y más población así como buscar nuevos productos en beneficio de este sector de población que ha elegido la forma cooperativa para satisfacer sus intereses de progreso en un ámbito de equidad y respeto a los derechos de las personas que los rodean.

Palabras clave: Cooperativas de ahorro y crédito; Centroamérica; Intermediación financiera.

Abstract: This study analyses the role carried out by saving and credit cooperatives in Central America where they have gained momentum, mainly in the past ten years. Cooperatives of this type are called financial intermediation cooperatives due to the influence of various legislative regulations that have placed them in the context of international control, the type of economic activity they perform and the fact that they make profits from both public and private international entities which enable their growth.

1 Catedrática Universidad de Costa Rica, Presidenta Asociación costarricense de Derecho Cooperativo. Correo electrónico: metanoia500@yahoo.es. 
Many of these organisations can be commended. They are highly competitive on financial markets and strive to extend their profits to increasingly larger parts of the population while also searching for new products to benefit the sector of the population that has chosen the cooperative model as a means to progress in a sphere of equity and respect for the rights of their fellow men.

Key words: Saving and credit cooperatives; Central America; financial intermediation. 


\section{Introducción}

El mundo financiero de las cooperativas de ahorro y crédito, en Centroamérica ha obtenido gran impulso en su desarrollo, en forma muy positiva, en los últimos diez años. Las cooperativas de ese tipo, denominadas como entidades cooperativas de intermediación financiera por influencia de las diferentes normas legislativas que las ha introducido dentro de las reglas de control internacional por el tipo de actividad económica que realizan, han crecido al interno y obtienen beneficios de entes estatales y privados internacionales que les permite crecer. Situación que no quita el mérito de muchas de estas organizaciones en cuanto a su competitividad en el mercado financiero y su afán por extender sus beneficios a más y más población así como buscar nuevos productos en beneficio de este sector de población que ha elegido la forma cooperativa para satisfacer sus intereses de progreso en un ámbito de equidad y respeto a los derechos de las personas que los rodean.

A pesar de la enorme heterogeneidad existente en el sistema de CAC-s, no hay duda que son una fuente muy importante formal o semi-formal de servicios financieros para la población de bajos ingresos, que llegan a sectores donde las demás instituciones microfinancieras (IMFs) no acceden. En una publicación de una cooperativa de ahorro y crédito de Costa Rica hace la pregunta sobre el por qué elegirla como la propia cooperativa y es en este ejemplo costarricense donde se encuentra una gran cantidad de servicios que ofrecen este tipo cooperativas. ${ }^{2}$ Otras cooperativas también ayudan en la administración de

2 «Coopealianza es la cooperativa de ahorro y crédito más grande en base asociativa de Costa Rica, actualmente es formada por más de 165.000 asociados. Además es una entidad financiera consolidada, con presencia en 30 cantones, por medio de 52 oficinas en todo el país. BENEFICIOS DE SER ASOCIADO A COOPEALIANZA. Dentro de las muchas ventajas que ofrecen son: a-Llegamos a más costarricenses, debido a nuestra cantidad de puntos de servicio, por ello, más personas pueden acceder a los créditos en el momento que lo requieran para lo que necesite. b-Con solo $\not 5.000$ de cuota mensual al Capital Social usted puede acceder a un crédito fácil y rápido con excelentes condiciones para que usted pueda cancelar una cuota baja. C. También puede contar con sistemas de ahorro que le permiten cumplir sus metas de acuerdo a sus necesidades, sea para estudios, viajes, compra de vehículo, entre otros. En Coopealianza nos preocupamos por el bienestar de sus asociados, por ello gracias al programa de Alianza Mutual, usted obtiene beneficios de manera gratuita, este programa le protege junto a su familia y a menores de edad, en caso de muerte, incapacidad total o permanente o accidente de un familiar. e-También puede obtener descuentos en universidades privadas y en comercios, así como la posibilidad de participar en rifas, promociones y actividades especiales durante todo el año. f-Además, usted puede acceder al sitio web www. coopealianza.fi.cr para realizar trámites y transacciones desde la comodidad de su hogar, para que aproveche más su tiempo. g-Si necesita el dinero rápidamente y sin filas, 
ciertos fondos, como en Costa Rica, los fondos del auxilio de cesantía, que hasta finales del siglo pasado eran intangibles y casi etéreos, pues estaban en manos de los patronos y no había seguridad en cuanto a su disposición por parte de los trabadores, sin embargo, con la promulgación de la Ley de protección al trabajador, en el año 1994, tales fondos pueden pasar a manos de los trabajadores en forma anticipada al cese de su relación laboral subordinada.

Por esa razón como un ejemplo de administración, se encuentra el comunicado que la cooperativa hace a sus agremiados, para hacerles conocer que tiene las autorizaciones legales para realizar tal actividad, la cooperativa se denomina COOPEBACEN, R. L. y la ampara la Ley Reguladora de la Actividad de Intermediación Financiera de las Organizaciones Cooperativas, (Ley 7391) en el Artículo 23, inciso ch), faculta a las Cooperativas de Ahorro y Crédito para administrar los recursos correspondientes a la cesantía de sus asociados, empleados de las entidades e instituciones públicas o privadas, en las que se haga una reserva para pagar la cesantía, si tal es la voluntad expresa del trabajador. Además obtuvo la aprobación de la Gerencia del Banco Central de Costa Rica para ser incluida como una entidad autorizada para la administración de la cesantía de los funcionarios del ente emisor y entes desconcentrados, en este caso los empleados del Banco Central de Costa Rica y Entes Desconcentrados que así lo tengan a bien, siempre y cuando sean asociados de COOPEBACEN, R.L.

En el presente ensayo se ha tomado en cuenta tres aspectos de importancia para las cooperativas de ahorro y crédito y el apoyo de los Estados centroamericanos al Cooperativismo de cada país, para desarrollar empresas y fortalecer al mismo movimiento cooperativo, como son la banca cooperativa y la banca de desarrollo social, el crecimiento o/y fortalecimiento de las CAC-S en Centroamérica, considerando las facilidades de acceso al crédito, muchos fondos provienen de entes externos al Cooperativismo y también de colaboraciones de países y fondos internacionales y el tercer aspecto se refiere a los incentivos a las cooperativas y su supervisión.

contamos con más de 500 cajeros automáticos de la red ATH en todo el país. Además puede realizar transferencias entre cuentas de otras entidades por medio del Sistema Nacional de Pagos Electrónicos (SINPE), plataforma tecnológica desarrollada y operada por el BCCR, que conecta al Sistema Financiero Nacional. h-Para más facilidad, le ofrecemos el sistema de cancelaciones automáticas, transferencias de dinero, deducción de planillas, de forma rápida evitándose filas y ahorrando su tiempo. i.-Como objetivo de Coopealianza también es ayudar a los empresarios, por lo que como entidad autorizada del Sistema Banca para el Desarrollo, ha otorgado más de 680 créditos para proyectos empresariales». 
La situación política y económica de los países centroamericanos no es la mejor, aunque ya han pasado los procesos bélicos, siguen existiendo los problemas de falta de alfabetización en muchos de aquéllos, alta migración a Estados Unidos, Costa Rica y Panamá por falta de oportunidades de empleo. Aunque Panamá ha sido beneficiado con la obtención de la propiedad de la empresa del Canal y la administración con recursos a favor del estado panameño y la continuidad en el crecimiento del mercado financiero e inmobiliario.

\section{Banca cooperativa y de desarrollo social}

En Costa Rica, la banca cooperativa desapareció como superestructura financiera del Cooperativismo en la década de los años noventa del Siglo Xx, durante el gobierno de la Presidenta Laura Chinchilla el Banco Popular y de Desarrollo Comunal fue intervenido y esa situación se prolongó durante todo el periodo presidencial, y su efecto nocivo fue el duro golpe al sector de Economía Social, por medio de la total restricción a la participación en sus máximos órganos decisión como son la Asamblea de trabajadores y trabajadoras, la Junta Directiva y el Directorio, que no se podían reunir porque había sido nombrada una Junta Directiva interventora.

Al desaparecer muchos de los entes cooperativos de segundo grado como FEDECRÉDITO R.L., que aglomeraba gran parte de las cooperativas de ahorro y crédito, los bancos cooperativos, VIVIENDACOOP R.L. que también tenía una parte de ahorro para vivienda a favor de las cooperativas y sus asociados que la integraban, así como la intervención de muchas cooperativas de intermediación financiera por parte de la Superintendencia de entidades financieras, el efecto fue una concentración de los cooperativistas en las cooperativas que sobrevivieron; muchas absorciones y fusiones de cooperativas con problemas y el fortalecimiento de otras cooperativas que crecieron no sólo en número de miembros sino en negocios financieros surgidos para favorecer a sus socios.

En este siglo, la sorpresa que dio COOPEMEX R.L, fue grande, pues se perfilaba como una cooperativa sólida y transparente en el Movimiento Cooperativo. Esta cooperativa un año antes iba a ser absorbida por COOPENAE R.L., la cual aumentaría en $50 \%$ su capital, pero no fue hecha a tiempo esa fusión y en uno de los periódicos de mayor circulación nacional se lee:

«La Superintendencia General de Entidades Financieras intervino la cooperativa de ahorro y crédito COOPEMEX para su investigación. La intervención de la entidad reguladora determinó, al menos por 90 días, el congelamiento de las cuentas de los 88000 clientes». 
Gabriela Mayorga escribió para Nacion.com: «Un comunicado de la Superintendencia indica que COOPEMEX tenía 'una cartera de crédito fuera de balance, cuyos deudores morosos no eran reportados, permitiendo reflejar una situación de morosidad distinta a la que realmente le correspondía'.»Fuente: Nacion.com»³.

La ausencia de un banco cooperativo ha sido suplida por la existencia del Banco Popular y de Desarrollo Comunal que en Costa Rica se ha perfilado como el brazo financiero del Cooperativismo más importante. Su labor ha sido reforzada por la existencia de la Ley del Sistema de Banca para el Desarrollo recientemente reformada que lo nutre como otros entes financieros públicos o privados de recursos con un destino definido.

Hernández y Zumbado (2012) han definido la banca de desarrollo como una herramienta de política pública orientada a estimular actividades económicas en los sectores empresariales más vulnerables, promoviendo más y mejores oportunidades de desarrollo, por medio de la colocación de recursos que en la práctica se constituyen como los fondos de «Banca Social», que sin bien es cierto, no están orientados a fortalecer la capacidad de emprender, éstos apoyan claramente la consolidación o crecimiento de las pequeñas empresas. ${ }^{4}$

En el caso del Banco Popular (BP), destaca el Fondo para el Desarrollo de las Micro, Pequeñas y Medianas Empresas (FODEMIPYME). Este fondo especial fue creado en el año 2002, enmarcado en la Ley del Fortalecimiento a las Pymes N. ${ }^{\circ} 8262$.

El objetivo es generar un mecanismo financiero directo que fomente y fortalezca el desarrollo de las MIPYME. Los recursos de este Fondo provienen del $5 \%$ de las utilidades del Banco Popular. Este fondo, se estructuró en tres sub fondos: el primero es para créditos, el segundo para avales y garantías y un tercero de transferencias para servicios de desarrollo empresarial. ${ }^{5}$

El Sistema de Banca para el Desarrollo tiene como objetivo fundamental generar políticas crediticias aplicables al sector MIPYME para promover el desarrollo, la productividad y la competitividad. El sistema busca

${ }^{3}$ CentralAmericaData.com, jueves 18 de febrero de 2010. Intervienen cooperativa Coopemex de Costa Rica.

4 HERNÁNDEZ, V. Y MORA, R. ( 2012): La Banca para el Desarrollo durante la crisis económica periodo 2008-2010, SERIES. ESBOZOS DEL DESARROLLO del Observatorio del Desarrollo, Universidad de Costa Rica, San José, N. ${ }^{\circ} 5$ publicación del 19/11/2012

5 HERNÁNDEZ Y MORA informan en documento citado p. 3 que estos tres fondos han movilizado, en forma acumulada desde el año 2004 hasta el año 2010, un total de $\not \subset 6.339,00$ millones de colones en créditos; $\not$ 9.972,00 millones de colones en avales y garantías; y $₫ 56.040,00$ millones de colones en servicios de desarrollo empresarial. 
proporcionar financiamiento por medio de mecanismos crediticios, fondos de avales y servicios no financieros de desarrollo empresarial.

Además, como se trata de un sistema, su deber es promover y facilitar la participación de entes públicos y privados, por medio de la integración y conformación de redes, de manera que se realice trabajo de fortalecimiento del desarrollo y la competitividad en beneficio del empresario MIPYME.

La Ley Constitutiva, en su artículo primero, define al SBD como «un mecanismo para financiar e impulsar proyectos productivos, viables $y$ factibles técnica y económicamente, acordes con el modelo de desarrollo del país en lo referente a la movilidad social de los grupos objeto de esta Ley». Los grupos objeto a los que hace referencia esta ley son las unidades productivas que cumplen con las características estipuladas en la Ley de Fortalecimiento de las Pequeñas y

Medianas Empresas N. ${ }^{\circ} 82622$.

La Ley del Sistema de Banca de Desarrollo N. ${ }^{\circ} 9274$ de 9 de octubre de $2014^{6}$ en su artículo número dos establece literalmente en el párrafo primero, que este sistema está integrado:

6 Entre los principales aspectos que incorpora el texto final aprobado están:

- Una mejor definición de los sujetos beneficiarios del SBD, haciendo énfasis en la inclusión financiera y en las microempresas.

- Se eliminan requisitos contraproducentes y redundantes exigidos a los beneficiarios del SBD, que los ponían en desventaja con el resto de usuarios del sistema financiero, tales como estudios de viabilidad ambiental para todos los proyectos.

- Se reconoce el papel jugado por las microfinancieras en la inclusión financiera y se incorporan como parte del SBD.

- La operacionalización de que los bancos privados puedan prestar directamente recursos, señalados en el punto anterior, a los sujetos beneficiarios del SBD, o por medio de banca de segundo piso.

- Se fortalece el mandato al Consejo Rector y al Banco que maneja el FINADE para que velen por la sostenibilidad financiera de tales fondos.

- Se faculta al FINADE para recibir recursos de contragarantía de entes públicos y privado y dar avales de cartera y no solamente individuales como hasta hoy.

- Los Fondos de Financiamiento para el Desarrollo (5\% de las utilidades anuales de los bancos de Estado) se les da una mayor claridad para que sigan siendo parte del patrimonio de los bancos estatales, solo que el uso responda a los criterios de esta ley.

- Se señalan los alcances para la aplicación de esta ley a la SUGEF y se le instruye para que aplique supervisión especial a las carteras de los bancos, basadas en las mejores prácticas internacionales para la inclusión financiera y el microcrédito.

- En el caso del INA se le instruye para que a través de una coordinación más estrecha con el Consejo Rector y la Secretaría Técnica del SBD, se logre sinergia en el apoyo a los sujetos beneficiarios del SBD. Igualmente el proyecto instruye a los entes públicos como MIDEPLAN, INFOCOOP e IMAS impulsar una mayor coordinación con el SBD para lograr los objetivos conjuntos. 
Artículo 2: «El SBD estará constituido por todos los intermediarios financieros públicos, el Instituto de Fomento Cooperativo (INFOCOOP), las instituciones públicas prestadoras de servicios no financieros y de desarrollo empresarial, y las instituciones u organizaciones estatales y no estatales que canalicen recursos públicos para el financiamiento y la promoción de proyectos productivos, de acuerdo con lo establecido en esta Ley. Queda excluido de esta disposición el Banco Hipotecario de la Vivienda (Banhvi).»

Cabe indicar que desde el año 2012 se calificó al Cooperativismo de ahorro y crédito como el "cuarto banco» del país - considerando los tres bancos estatales-, aunque por separado las treinta entidades cooperativas de este sector, que son supervisadas por la Superintendencia General de Entidades Financieras (Sugef), son muy pequeñas financieramente, pero en su conjunto manejan recursos similares a principales bancos como cuentas de ahorro, préstamos y pagos de servicios domiciliarios y a empresas privadas atraen a nueva clientela. ${ }^{7}$

Refiere ARIAS, J. (2012) sobre este conjunto de cooperativas:

"La cooperativa más grande es Coopenae, con activos por $\not 402.000$ millones, superiores a los de bancos como Lafise, Improsa, BCT, General, Cathay y Bansol. ¿A quienes atienden? La presencia de bancos a lo largo del país no ha sido obstáculo para que las cooperativas de ahorro y crédito logren hacerse de nuevos clientes. Los pequeños ahorrantes y los microempresarios, que además suelen ser asociados de la cooperativa, son su principal clientela. "Nuestros clientes se convierten también en dueños, con una participación en el patrimonio cooperativo y eso les ofrece ventajas adicionales», expresó Adrián Álvarez, subgerente de Coopenae. Sobre el destino de los recursos que prestan, estos se utilizan para consumo, vivienda y financiamiento de pequeñas empresas. "Este sector se dirige a las personas de ingresos medios y bajos, principalmente trabajadores. Aquí se incluye al pequeño y mediano productor o empresario y a educadores o funcionarios públicos», manifestó Óscar Hildago, gerente de Coopeservidores. De acuerdo con el funcionario, en el rubro de ahorros el conjunto de cooperativas maneja un $10 \%$ del total del sistema financiero. Ventajas. Con cuentas de ahorro, certificados de depósito, préstamos y pagos de servicios, las cooperativas logran un lugar entre los bancos, financieras y mutuales. Además, consiguen una combinación de tasas de interés subsidiadas para créditos y altas para ahorros. ¿Cómo lo hacen? Según Hidalgo, una buena parte del fondeo proviene de débitos automáticos

7 COOPENAE R.L., Cooperativa de educadores, desde el año 2001 se consolidó como la cooperativa líder de ahorro y crédito en Costa Rica y la quinta cooperativa en el nivel latinoamericano en el año 2011. 
a las planillas de los asociados. También este mecanismo les permite estar en el grupo de entidades con más baja morosidad. Berny Calderón, gerente de Coocique, explicó que los clientes que son asociados tienen derecho a distribución de excedentes, subsidios, capacitaciones y fondos de mutualidad, entre otros» ${ }^{8}$.

En relación con Panamá las estadísticas al año 2010 del Instituto Panameño Autónomo Cooperativo (IPACOOP), Panamá tenía 521 cooperativas, las cuales manejaban un total de $\$ 1.400$ millones y un $80 \%$ provee servicios múltiples o de ahorro y crédito. Ana Giselle Rosas de Vallarino, Directora del Instituto, destacó el crecimiento sostenido que tenido por este tipo de asociaciones en los últimos tres años, e indicó que la fiscalización en el manejo de los recursos se vuelve cada vez más importante. Así como la capacidad legal del Instituto de inspeccionar a las cooperativas para hacerles auditorías, verificar sus libros sociales y que las actas han sido aprobadas, que las juntas de vigilancia estén haciendo su trabajo y cuando se trata de cooperativas de ahorro y crédito estén cumpliendo con los requisitos para aprobar préstamos. ${ }^{9}$

\section{Crecimiento y/o fortalecimiento de las CAC-S en centroamerica: acceso al credito y supervision}

En Costa Rica las cooperativas de intermediación financiera, por el volumen de sus activos y de las carteras de crédito que administran, en su conjunto son el cuarto mayor operador financiero del país ${ }^{10}$.

8 ARIAS, P.: Entidades de ahorro y crédito se dirigen a la población de ingresos medios y bajos Sector cooperativo es el 'cuarto banco' más grande del país. Ed. Lanacion. com 29 de octubre de 2012.

9 CentralAmericaData.com, martes 23 de noviembre de 2010 cita publicación martesfinanciero.com. Cooperativas al alza en Panamá. La figura de la cooperativa cobra cada vez más relevancia en el país, especialmente en servicios múltiples y de ahorro y crédito.

10 SAGOT, M. en su artículo (2013) «El sistema financiero en los últimos 25 años», en Revista Academia de Costa Rica, San José, p. 35 al referirse a la posición de las cooperativas de ahorro y crédito en Costa Rica analiza lo siguiente: «A partir del 2000 se observa un proceso de consolidación y estabilidad del sector, con una participación no despreciable dentro del SFCR. El número se entidades tendió a estabilizarse, mientras que su participación en el sistema financiero fue en ascenso. En efecto, el peso relativo del activo, pasivo y la cartera crediticia dentro del SFCR más que se duplicó entre el 2000 y el 2012. Asimismo, se observa un fortalecimiento patrimonial a lo largo de ese período. La desaparición de muchas cooperativas pequeñas dio paso a otras cuyo tamaño aumentó significativamente. En la actualidad sobresalen 4 entidades, tres urbanas con sede en San José (COOPENAE, COOPESERVIDORES y ANDE), y una en la zona rural con sede en San Isidro de El General (COOPEALIANZA). En conjunto totalizan poco más del 70 por ciento de los activos totales del sector». 
El Banco Popular y de Desarrollo Comunal desde el año 2009 dispuso de $\$ 35$ millones para MiPyMEs costarricenses. Los fondos provienen de las utilidades de la institución y se asignaron mediante la primera subasta de avales y garantías que llevada a cabo el 20 de febrero de ese año por el Fondo de Desarrollo de las Micro, Pequeñas y Medianas Empresas (FODEMIPYME). ${ }^{11}$

Entre las favorecidas se encuentran seis cooperativas: COOPEFYL R.L., COOCIQUE R.L., COOPENAE R.L., COOPEALIANZA R.L., COOPESERVIDORES R.L. Y COOPEMEX R.L. Estos avales se aplicaron a cubrir hasta el $75 \%$ de cada crédito solicitado, luego de evaluar la factibilidad del proyecto para el cual se solicitaban los recursos.

Parte de los estudios para otorgar esos avales y garantías es el resultado obtenido en ese año, donde las 30 cooperativas supervisadas por la Superintendencia General de Entidades Financieras (SUGEF) superan en valor de activos y en cartera de crédito "al banco privado BAC San José y se encuentran por debajo de los bancos Nacional, Costa Rica y Banco Popular y de Desarrollo Comunal, de capital público.

Debe tenerse en cuenta que existen otras 40 instituciones cooperativas cuya supervisión no corresponde a la SUGEF, que también realizan operaciones de crédito. La cooperativa más grande es COOPENAE R.L., con activos por $₫ 402.000$ millones [ $\$ 808$ millones], superiores a los de bancos como Lafise, Improsa, BCT, General, Cathay y Bansol.

Óscar Hildago, gerente de Coopeservidores, en una entrevista realizada por Lanación.com, citada por CentralAmericadata, expresó: «en el rubro de ahorros el conjunto de cooperativas maneja un $10 \%$ del total del sistema financiero» ${ }^{12}$.

En El Salvador las CAC-S han experimentado un incremento importante, entre 2006 y 2013 se duplicó el número de agencias de la red de cooperativas con el objetivo de expandir los servicios financieros en el país. La Federación de Asociaciones Cooperativas de Ahorro y Crédito de El Salvador (FEDECACES) ha comunicado que "el crecimiento está respaldado por un incremento de más del $20 \%$ en la cartera de créditos y depósitos, luego del cierre de 2013».

Las Cooperativas de Ahorro y Crédito (CAC) en Honduras han sido fundamentales para el acceso y disponibilidad de servicios financieros en el área rural y urbana del país, especialmente para personas de bajos ingresos, quienes tradicionalmente han sido relegados de los servicios finan-

11 CentralAmerica.Data.com (2009).Las PyMEs de Costa Rica podrán recibir recursos respaldados por garantía, para proyectos viables.

12 CentralAmerica.Data.com (2009): Las PyMEs de Costa Rica podrán recibir recursos respaldados por garantía, para proyectos viables. 
cieros de calidad. Mientras que el sector financiero concentra el $71 \%$ de sus operaciones en las grandes ciudades, las CAC concentran alrededor de éstas el $54 \%$ y el $45 \%$ restante corresponde a operaciones rurales. No obstante el esfuerzo efectuado por llegar a zonas relegadas de atención, se requiere profundizar más sus acciones y llegar a zonas y poblaciones en donde los servicios financieros son prácticamente inexistentes.

En los últimos 10 años, la Federación de Cooperativas de Ahorro y Crédito de Honduras (FACACH) ha asumido un papel central en la introducción de nuevos conceptos y prácticas para fortalecer al sector. Ha creado una alianza estratégica de cooperativas denominado UNIRED, en el cual la participación está únicamente basada en el desempeño financiero de las cooperativas, medido bajo la metodología PERLAS del World Council of Credit Unions (WOCCU). Se logró implementar una red de recepción de remesas y de servicios de compensación entre cooperativas, lo cual les permite lograr una parcial cobertura nacional. Estos servicios tienen una alta demanda, que no se puede atender dado que se manejan de manera rudimentaria (las transferencias se efectúan vía fax) lo que exige una capacidad operativa cada vez mayor, la cual, por otra parte está sujeta a errores que un sistema tecnológico apropiado ayudaría a evitar ${ }^{13}$.

En cuanto a Nicaragua las cooperativas están solicitando en el mercado de la reforma de concertación tributaria que se elimine la retención del $1 \%$ mensual sobre sus ingresos brutos y que se cree una normativa tributaria especial.

La Ley de Concertación Tributaria indica que las cooperativas están libres de pagar el impuesto sobre la Renta si sus ingresos brutos anuales son inferiores o iguales a $\$ 1,5$ millones. Sin embargo, esta misma ley también señala que debe retenerse el $1 \%$ mensual de forma anticipada aunque no se alcance el ingreso indicado ${ }^{14}$.

\section{Incentivos a cooperativas}

Los Estados centroamericanos han venido impulsando al Cooperativismo con diferentes beneficios para su desarrollo, en el año 2013 el

13 Véase en Fortalecimiento institucional de las cooperativas de ahorro y crédito de Honduras, Documento del Banco Interamericano de Desarrollo. Fondo Multiraleral de Inversiones. recuperado de http://idbdocs.iadb.org/wsdocs/getdocument. aspx?docnum $=431327$

14 CentralAmericaData. com, lunes 8 de diciembre de 2014. Nicaragua: Retención para renta a cooperativas. 
Gobierno salvadoreño exoneró de pago de impuestos municipales y del pago de la renta a 16 cooperativas, este beneficio es por cinco años, prorrogable por periodos iguales, a petición de cada cooperativa y debe mediar acuerdo ejecutivo del ramo de Economía previa audiencia del Ministerio de Hacienda. El beneficio se puede obtener para gozarlo en forma parcial o total según el artículo 72 de la Ley general de Asociaciones Cooperativas que reza:

«Los siguientes privilegios serán concedidos a petición de la Cooperativa interesada por acuerdo ejecutivo en el Ramo de Economía, total o parcialmente, previa justificación con audiencia del Ministerio de Hacienda, por el plazo de cinco años, a partir de la fecha de su solicitud y prorrogables a petición de la Cooperativa por períodos iguales:

a) Exención del impuesto sobre la Renta, Vialidad y Territorial Agropecuario, cualquiera que sea su naturaleza, el capital con que se forma, intereses que se generen a partir del ejercicio fiscal durante el cual se presente la solicitud.

b) Derogado.

c) Exención de impuestos fiscales y municipales sobre su establecimiento y operaciones.»

Bajo la consideración del peso en la economía salvadoreña del Cooperativismo, el gobierno salvadoreño de Mauricio Funes se comprometió con este importante actor social y económico, pues considera a las asociaciones cooperativas como uno de los agentes económicos en los cuales se va a sustentar el nuevo modelo económico y social que promueve el gobierno. Según el gobierno salvadoreño el sector cooperativo es una pieza clave de todo este sistema, es parte esencial del tejido empresarial al que se le está apostando. Las cooperativas son actores fundamentales del desarrollo en el país, por ello, desde el inicio de la gestión presidencial, en el Plan Quinquenal de Desarrollo se planteó la elaboración e impulso de políticas macroeconómicas y sectoriales de fomento, necesarias para estimular la producción nacional y ampliar la base empresarial mediante el apoyo a las micro, pequeñas y medianas empresas y también a las distintas escalas de producción nacional. Las asociaciones cooperativas en la actualidad han demostrado su capacidad de incidir en la economía del país, como verdaderas empresas que alcanzan a una importante cantidad de la población y a una amplia diversidad de sectores económicos, produciendo bienes y servicios mediante la asociatividad con finalidad no lucrativa.

También están pensadas algunas reformas a la Ley de Creación del Instituto Salvadoreño de Fomento cooperativo, para fortalecer la rectoría de la institución en sus funciones de fomento y control de las aso- 
ciaciones cooperativas. Se persigue que los recursos económicos con que operará el instituto estén consignados en el Presupuesto General de la Nación en el Ramo de Economía, tomando en consideración las necesidades del Programa Nacional de Incentivos a la Inversión Privada y del fomento de las Asociaciones Cooperativistas. Con la reforma se busca que el INSAFOCOOP sea una entidad adscrita al Ministerio de Economía y deje de ser parte del Ministerio de Trabajo, tal como aparece actualmente ${ }^{15}$.

Para conocer la incidencia del Cooperativismo Salvadoreño en la economía de ese país, de los datos obtenidos del INSAFOCOOP, durante el período 2004-2009, en seis años, solamente 155 asociaciones cooperativas obtuvieron el beneficio de exención de impuestos, mientras que durante el período de 2010 a febrero 2013, es decir, en los tres años de la actual administración, se ha beneficiado a 176 asociaciones cooperativas. Durante el gobierno del presidente Mauricio Funes se han legalizado 565 asociaciones cooperativas agropecuarias inscritas en el Ministerio de Agricultura y Ganadería.

Destaca en la dimensión económica las asociaciones cooperativas captan más de $\$ 503,4$ millones en pequeños ahorros que se reinvierten en créditos en los mismos municipios, generando actividad económica y tributación local.

Además, generan más de $\$ 7,1$ millones en impuestos indirectos de IVA sobre sus volúmenes de operaciones y en su rol de agentes de retención, lo que supera la exención del pago del impuesto sobre la renta estimado en $\$ 4.9$ millones. En el país hay alrededor de 306.406 asociados que se desglosan en 787 cooperativas registradas en el INSAFOCOOP y 1719 asociaciones reportadas por el Ministerio de Agricultura y Ganadería en sector reformado, no reformado y pesqueras. Del total de personas asociadas a nivel nacional el $58 \%$ son hombres y el $42 \%$ son mujeres.

Con un aporte de \$2.7 millones la Unión Europea y el Gobierno de El Salvador fomentan el entorno cooperativo del país, a partir del 10 de noviembre de 2011 se realizó el lanzamiento del Fideicomiso de Desarrollo Cooperativo Salvadoreño - FIDECOSAL, para otorgar recursos crediticios a las Asociaciones Cooperativas legalmente establecidas en El Salvador, como una forma de continuar estimulando los recursos potenciales en el entorno cooperativo, así como fomentar su participación como agentes productivos del país, FIDECOSAL busca potenciar el desarrollo del sector cooperativo, contribuyendo a mejorar las condiciones

15 CentralAmericaData.com, viernes 22 de marzo de 2013. 
de vida de los asociados y sus familias, mediante el financiamiento de actividades productivas del sector agropecuario, agroindustria, pesca, acuicultura, artesanías y servicios de ecoturismo.

FIDECOSAL ha sido constituido por el Instituto Salvadoreño de Fomento Cooperativo (INSAFOCOOP) y cuenta con una aportación de \$ 2,700,000 provenientes de la Unión Europea y del Gobierno de El Salvador, en seguimiento al Convenio de Cooperación suscrito entre la Unión Europea y los países centroamericanos y Panamá denominado: Programa Regional de Fomento a las Cooperativas en el Istmo Centroamericano - PROCOOPCA. Los sujetos de crédito del Fideicomiso de Desarrollo Cooperativo Salvadoreño - FIDECOSAL son las instituciones financieras, en calidad de entidades intermediarias y los usuarios finales son las Asociaciones Cooperativas de producción y de ayuda a la producción, legalmente establecidas en El Salvador. Los créditos otorgados tienen un límite de $\$ 25,000^{16}$.

Tanto en Guatemala como en Costa Rica oportunidades de desarrollo para las cooperativas eléctricas se han dado. Permitiendo incentivos relacionados con la elaboración de proyectos y su financiamiento para su ejecución en Guatemala, o bien con una supervisión diferenciada en cuanto al segundo país.

A través de la Confederación Guatemalteca de Federaciones Cooperativas (CONFECOOP), las cooperativas agremiadas cuentan con los proyectos, financiamiento y programas de ejecución para la construcción de pequeñas plantas hidroeléctricas, cuyos propietarios serán las cooperativas. Mediante un convenio firmado por la Federación con la Asociación Nacional de Cooperativas Eléctricas Rurales de EE. UU., surgió una alianza para brindar asistencia, organización, estrategia y una política para las cooperativas eléctricas del país en administración y gestión. El señor Rodolfo Orozco, director ejecutivo de CONFECOOP, indicó a Prensalibre.com : «Realizamos los últimos ajustes del plan de inversión y los aportes del suministro a la red, y esperamos presentar los proyectos en junio' ${ }^{17}$.

Las cooperativas electrificación rural de Costa Rica obtuvieron un tratamiento distinto a las cooperativas en general, para el financiamiento de sus proyectos mediante emisión de deuda así como un reco-

16 La Unión Europea apoya el desarrollo cooperativo en El Salvador (10/11/2011) Publica Delegación de la Unión Europea en El Salvador, http://eeas.europa.eu/delegations/el_salvador/press_corner/all_news/news/2011/20111111_es.htm

17 CentralAmericaData.com, viernes 18 de mayo de 2012. El potencial financiero de cooperativas de Guatemala se volcará en el desarrollo de proyectos de energía renovable. 
nocimiento de la Contraloría General de la República en cuanto a la especial naturaleza de su actividad, cuando ésta entidad señaló:

«La Procuraduría General de la República aclaró a la Superintendencia General de Valores (SUGEVAL), que no se pude medir a estas entidades con la misma vara, que a las cooperativas de ahorro y crédito.»

Indicó la PGR que la SUGEVAL debería emitir un reglamento específico para que las cooperativas de electrificación rural puedan participar del Mercado de Valores, ya que algunas de las disposiciones de la Ley de Fortalecimiento y Modernización de las Entidades Públicas del Sector Telecomunicaciones se extienden a las cooperativas de electrificación rural o repercuten en ellas, de tal modo que requieren de una supervisión distinta a la establecida en el Instituto de Fomento Cooperativo. La Procuraduría «considera que la Ley hace una derogación implícita de los principios del cooperativismo para que estas cooperativas puedan contribuir a satisfacer los objetivos del sistema eléctrico nacional y, en particular de las zonas donde están establecidas para abastecer a la población» ${ }^{18}$.

Otras oportunidades de financiamiento se encuentran en casos concretos como es la cooperativa COOPENAE R.L. Cooperativa Nacional de Educadores que en el año 2011 recibió $\$ 30$ millones para PyMEs e hipotecas de la Corporación Financiera Internacional (IFC) para créditos hipotecarios para familias de bajos ingresos y financiamiento para pequeñas y medianas empresas. La IFC, dependencia del Banco Mundial, entregó \$15 millones en colones más otros $\$ 15$ millones, también en colones, proporcionados por FMO, el Banco de Desarrollo de Holanda ${ }^{19}$.

En Honduras se reformaron 47 artículos de ley de Cooperativas y se introdujo un acuerdo con el movimiento cooperativo Hondureño para crear el Consejo Nacional Supervisor de Cooperativas, (CONSUCOOP), institución descentralizada del Estado, autónomo y con patrimonio propio, a cargo de la aplicación de la legislación cooperativa y autoridad de control de los entes cooperativos. El órgano de dirección del CONSUCOOP es la junta directiva que estará integrada por el presidente de la Confederación Hondureña de Cooperativas (CHC.) o su represen-

18 CentralAmericaData.com, lunes 4 de marzo de 2013, Emisión de valores por cooperativas de electrificación. Las cooperativas de electrificación rural de Costa Rica tendrían un tratamiento distinto a las cooperativas en general, para el financiamiento de sus proyectos mediante emisión de deuda.

19 CentralAmericaData.com, jueves 28 de julio de 2011. Costa Rica: $\$ 30$ millones para PyMEs e hipotecas. La Cooperativa Nacional de Educadores (Coopenae) recibirá $\$ 30$ millones de la Corporación Financiera Internacional (IFC) para créditos. 
tante, quien lo presidirá; el ministro de Industria y Comercio, o su representante; el ministro de Finanzas, o su representante; el ministro de Educación o su representante; el titular de Agricultura y Ganadería o su representante; y cuatro representantes del movimiento Cooperativista electos por tres años por la asamblea general de la $\mathrm{CHC}^{20}$.

En Guatemala se ha venido buscando introducir la supervisión de las cooperativas de ahorro y crédito asociadas a MICOOPE (marca que aglutina a las Cooperativas Federadas de ahorro y crédito de todo ese país.

Lorena Álvarez informó en Elperiodico.com.gt, «La propuesta busca integrar a las cooperativas que prestan servicios financieros dentro del sistema regulado, como ocurre en la mayoría de países de América Latina, explicó Eduardo Soto, supervisor del área de desarrollo de normativa de la Superintendencia de Bancos $(\mathrm{SIB}){ }^{21}$.

La COLAC Confederación de cooperativas de Latinoamérica, en Panamá, firmó un convenio el 9 de abril de 2014 con IPACOOP, Instituto Panameño de Cooperativas para ofrecer un modelo de disciplina financiera a disposición del sector de cooperativas de ahorro y crédito, en el cual se generan el cálculo de indicadores de gestión y financiero lo cual permitirá la evaluación del riesgo, la calificación de su desempeño y la propuesta de acciones de mejoramiento continuo y fortalecimiento de la institución 22 .

\section{Conclusiones}

La región centroamericana tiene un Cooperativismo fuerte y pujante en la organización de los sistemas de crédito cooperativo. Los gobiernos se han comprometido con la población ubicada como clase media y de bajos recursos impulsando programas de financiamiento para el desarrollo de pequeñas y medianas empresas, donde el Cooperativismo de cada país, juega un importante papel.

La experiencia de cada país en el campo cooperativo es de gran ayuda para el desarrollo de planes y la aplicación de fondos a las em-

20 CentralAmericaData.com, jueves 29 de agosto de 2013 Nueva Ley de Cooperativas en Honduras. La reforma de 47 artículos de la antigua Ley de Cooperativas y la adición de otros 14 fue consensuada por el movimiento cooperativo hondureño.

21 CentralAmericaData.com, lunes 12 de febrero de 2011.Guatemala: Las cooperativas de crédito serán supervisadas. El ente regulador prepara la normativa para incluir a las cooperativas de crédito bajo su supervisión.

22 COLAC, recuperado de http://www.colac.coop/index.php/noticias-actualidad/noticias-cooperativas/325-colac-firma-convenio-con-el-ipacoop-el-9-de-abril-de-2014 
presas cooperativas y no cooperativas. Esencialmente las cooperativas de ahorro y crédito, denominadas en Costa Rica, como empresas cooperativas de intermediación financiera, las cuales en las últimas dos décadas han tenido que someter su actividad al control de entes supervisores de su actividad en la intermediación financiera, para determinar los riesgos de la misma, la capacidad financiera atender sus obligaciones con sus asociados y acreedores, la suficiencia patrimonial, la adecuada capitalización de los recursos, entre otros. La buena calificación ha ubicado tales cooperativas en una posición sólida y confiable para obtener grandes sumas de capital e impulsar sus propios proyectos financieros así como colaborar con otras empresas cooperativas o no, que requieren de un financiamiento dirigido y controlado según los objetivos del proyecto productivo.

El balance para Centroamérica es positivo. En la mayoría de los países que forman esa región, existen políticas bancarias como la banca de desarrollo, y de supervisión al cumplimiento de requisitos para obtener financiamiento y en la ejecución de múltiples proyectos productivos o, en la atención de necesidades de los socios de las cooperativas que reciben tales recursos, como son: educación, formación empresarial, avales y garantías para iniciar nuevos proyectos productivos, entre otros.

Hay algunas amenazas sentidas por los cooperativistas en algunos países, como es la carga impositiva que en un futuro no muy cercano se prevé será establecida, según la antigüedad de la cooperativa y el grado de su desarrollo económico. Es inevitable, pues ha cambiado mucho la política en los Estados del mundo y Centroamérica no puede escapar al cambio en cuanto la reducción de beneficios por razón de la actividad cooperativa, en forma permanente y permitir un desarrollo individual dirigido a posicionarse en el mercado financiero con todas las herramientas de supervisión, educación y know how obtenido en los años de existencia de cada cooperativa.

\section{Bibliografía}

ARIAS, P.: Entidades de ahorro y crédito se dirigen a la población de ingresos medios y bajos Sector cooperativo es el 'cuarto banco' más grande del país, Ed. Lanacion.com 29 de octubre de 2012.

BID: Fortalecimiento institucional de las cooperativas de ahorro y crédito de Honduras, Documento del Banco Interamericano de Desarrollo. Fondo Multiraleral de Inversiones: http://idbdocs.iadb.org/wsdocs/getdocument. aspx? docnum $=431327$ COBACEN R.L

CentralAmericaData (2009): Las cooperativas financieras de Costa Rica 
CentralAmericaData. com, lunes 8 de diciembre de 2014.

CentralAmericaData.com, jueves 28 de julio de 2011

CentralAmericaData.com, jueves 29 de agosto de 2013

CentralAmericaData.com, lunes 12 de febrero de 2011.

CentralAmericaData.com, lunes 4 de marzo de 2013.

CentralAmericaData.com, viernes 18 de mayo de 2012.

CentralAmericaData.com, viernes 22 de marzo de 2013.

COLAC: http://www.colac.coop/index.php/noticias-actualidad/noticias-cooperativas/325-colac-firma-convenio-con-el-ipacoop-el-9-deabril-de-2014

HERNÁNDEZ, V. y MORA, R. (2012): La Banca para el Desarrollo durante la crisis económica periodo 2008-2010, series. esbozos del desarrollo del Observatorio del Desarrollo, Universidad de Costa Rica, San José, N. ${ }^{\circ}$ publicación del 19/11/2012, http://odd.ucr.ac.cr/sites/default/files/esbozos/ Banca_Desarrollo_imprenta.pdf

Http://www.centralamericadata.com/es/article/home/Costa_Rica

SAGOT, M. (2013): «El sistema financiero en los últimos 25 años», en Revista Academia de Costa Rica, San José, http://www.google.co.cr/url?sa=t\&rct= $j \& q=\& e s r c=s \& f r m=1 \&$ source $=$ web \&cd $=10 \& v e d=0$ CFEQFjAJ\&url $=$ http $\% 3 \mathrm{~A}$ $\% 2 F \% 2 F w w w$.academiaca.or.cr\%2Fwp-content\%2Fuploads \%2F2014\% 2F03\%2FMOMOGRAFIA-1-Loria-CARTA2- 